\title{
Clinico - Radiological Study of Skeletal Dysplasias
}

\author{
B. Vanaja ${ }^{\circledR 1}$, M Veena ${ }^{\circledR 2}$, Shivaji Gogi ${ }^{2}$ \\ ${ }^{1}$ Assistant Professor, Department of Radiology, Osmania Medical College, Hyderabad, Telangana, India, ${ }^{2}$ Associate Professor, Department of Radiology, Osmania \\ Medical College, Hyderabad, Telangana, India.
}

\section{Abstract}

Background: Skeletal dysplasia and osteochondrodysplasia refer to a genetically and clinically heterogeneous group of disorders of skeletal development and growth. Their prevalence is about 1 in 4000 births. Skeletal dysplasia is prevalent worldwide and its prevalence varies in different parts of the world and even in the same country varies from region to region. The objective is to study the prevalence of skeletal dysplasia based on clinico-radiological features. Subjects and Methods: A hospital retro prospective based study of skeletal dysplasia's was conducted over a period of 2 years in which 100 cases of skeletal dysplasia's were studied and were grouped according to international classification of osteochondrodysplasia' s revised in 2006. Results: 100 cases of skeletal dysplasia's were detected by various modes of examination like clinical, radiological (radiographs, USG, CT scan, MRI, echocardiography), genetic and biochemical tests. Among 100 cases 22 cases showed clinico-radiologically concordance, 45 cases showed clinico-radiological complement and 40 cases showed clinico-radiological discordance. Conclusion: Our study makes an important observation that only clinical evaluation detected only $20 \%$ of skeletal dysplasia's; and hence the importance of clinic-radiological evaluation in the proper diagnosis of skeletal dysplasia's.

Keywords: Skeletal dysplasia, Short limb dwarfism, Radiograph, Skeletal survey, Review, Spondyloepiphyseal dysplasia, Multiple epiphyseal dysplasia

Corresponding Author: M Veena, Associate Professor, Department of Radiology, Osmania Medical College, Hyderabad, Telangana, India. E-mail: drveena06@gmail.com

Received: 13 May 2020

Revised: 18 June 2020

Accepted: 26 June 2020

Published: 5 July 2020

\section{Introduction}

Dysplasia is a developmental abnormality; in the pathology, size, shape and organization of adult cells. ${ }^{[1]}$ Osteochondrodysplasia $s$ are a broad category of heterogeneous disorders comprising of bone or cartilage abnormalities or structure. A number of over 350 diseases are associated with the osteochondrodysplasia and dysostasis. ${ }^{[2]}$ Their genetic variants tend to evolve during their lives. They exist due to genetic variants. Skeletal dysplasia therefore varies from dysostoses that include malformations of single or several bones attributable to pathological in-utero blastogenesis and remain unchanged throughout the lifespan phenotypically. ${ }^{[3]}$ Today more than 450 entities focused on radiological, molecular and biochemical parameters have been identified. ${ }^{[4]}$ Although certain dysplasia's are quite rare individually, in various epidemiological studies, their overall prevalence as a group was 2.3-7.6 in 10000 births. ${ }^{[5-8]}$

Few dysplasia's become fatal at perinatal level. They arise in non-lethal dysplasia with extreme small height or inability to attain longitudinal development or certain physical deformities in the early childhood. The condition is observed on antenatal ultrasound scans. Dysplasia may be accurately identified based on the combination of clinical and family history, physical assessment, radiological evaluation and molecular and biochemical testing. One of the main elements of a diagnostic study of dysplasia is the radiology assessment. A general radiologist will often find a patient with suspected skeletal dysplasia in a series of $\mathrm{x}$-rays. While certain dysplasia's can quickly be identified on the basis of some features or what are regarded as textbook results, a careful approach to diagnostics is important. In this article, we discuss the radiological method for the diagnosis of nonlethal dysplasia and identify the radiological features of many significant and more severe non-lethal dysplasia's afterwards.

\section{Subjects and Methods}

Place of Study: Department of Radiology, Niloufer Hospital for women and children.

Type of Study: It is a hospital based Cross sectional study with consecutive sampling. 
Duration: Two Years i.e. January 2018 to December 2019.

Sample Size: 100 Children.

\section{Inclusion criteria:}

- All the cases of skeletal dysplasia's referred to the department of radio diagnosis

- Skeletal dysplasia cases detected at birth during the study period.

- Cases with skeletal dysplasia were included irrespective of the age and sex.

\section{Exclusion criteria:}

- Patients who don't meet the criteria of definition of skeletal dysplasia parse.

- Those patients who refuse to be included in the study.

Informed consent from all the patients was taken before undergoing the study. All cases of skeletal dysplasia referred to the department of radio- diagnosis and all the consecutive births were screened for presence of skeletal dysplasia's, after studying family history, genetic history, obstetric history, antenatal history. The cases underwent a detailed anthropometric measurement like height, weight, upper segment length, lower segment length, upper segment to lower segment ratio, head circumference, chest circumference.

\section{Method of Examination:}

All cases referred to the department of Radio- diagnosis with high degree of clinical suspicion of skeletal dysplasia were evaluated with skeletal survey as per the recommendation by Wynne-Davies 30.

They included:

1. Skull X-ray lateral view.

2. Antero-Posterior and lateral view of spine (T1-S1).

3. Chest Posterior -Anterior view including shoulders.

4. Pelvis/hips.

5. Antero-Posterior view of one knee.

6. Antero-Posterior view of one forearm.

7. Posterior-Anterior view of hand/ wrist

8. Feet Antero-Posterior view including ankle.

For new born and small babies, Antero-Posterior and lateral film of the whole body was taken (infantogram).

\section{Results}

This study was performed to detect skeletal dysplasia prevalence and categorization in the latest International Nosology 20063 of patients with skeletal dysplasia's in new-born's and to relate clinical diagnosis to radiological diagnosis.

\begin{tabular}{ll}
\hline \multicolumn{2}{l}{ Table 1: Age and sex wise distribution of skeletal dysplasia's } \\
\hline Age group & Total \\
\hline Abortus / Stillborn & 03 \\
\hline Neonates & 23 \\
\hline Infants & 11 \\
1-4 years & 15 \\
4-8 years & 22 \\
8-12 years & 06 \\
12 years and above & 20 \\
Total & $\mathbf{1 0 0}$ \\
\hline Sex & \\
\hline Male & 56 \\
\hline Female & 44 \\
\hline
\end{tabular}

Table 2: Showing distribution of cases based on consanguinity

\begin{tabular}{llll}
$\begin{array}{l}\text { Total no. Of } \\
\text { cases }\end{array}$ & $\begin{array}{l}\text { Consanguineousl! } \\
\text { married couples }\end{array}$ & $\begin{array}{l}\text { Non- } \\
\text { consanguineously } \\
\text { married couples }\end{array}$ \\
100 & & 48 & 52 \\
\hline
\end{tabular}

The number of cases examined for skeletal dysplasias showed a very high degree of consanguinity majority being uncle-niece marriage.

Type 2 Collagen group, Filamin and FGFR3 group, Lysosomal storage disease with skeletal development were observed majorly in the entire study population.

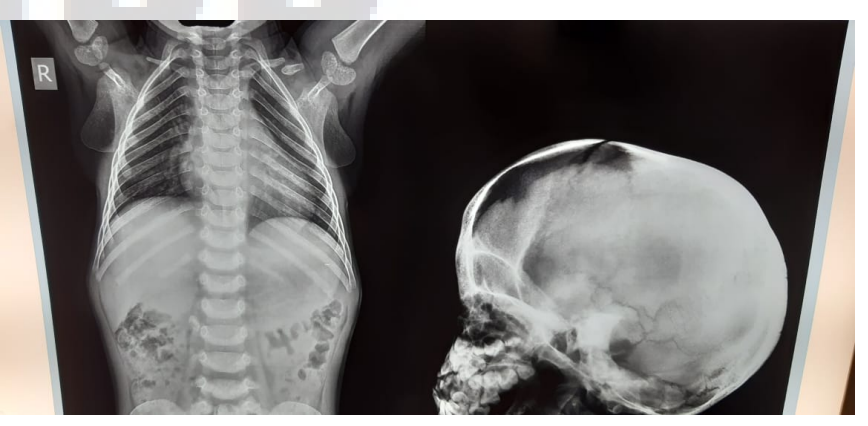

Figure 1: Cleido Cranial Dysplasia

100 cases of skeletal dysplasia's were detected by various modes of examination like clinical, radiological (radiographs, USG, CT scan, MRI, echocardiography), genetic and biochemical tests. Among 100 cases 22 cases showed clinico-radiologically concordance, 45 cases showed clinicoradiological complement and 40 cases showed clinicoradiological discordance. 
Table 3: Classification of skeletal dysplasias based on international nosology 2006






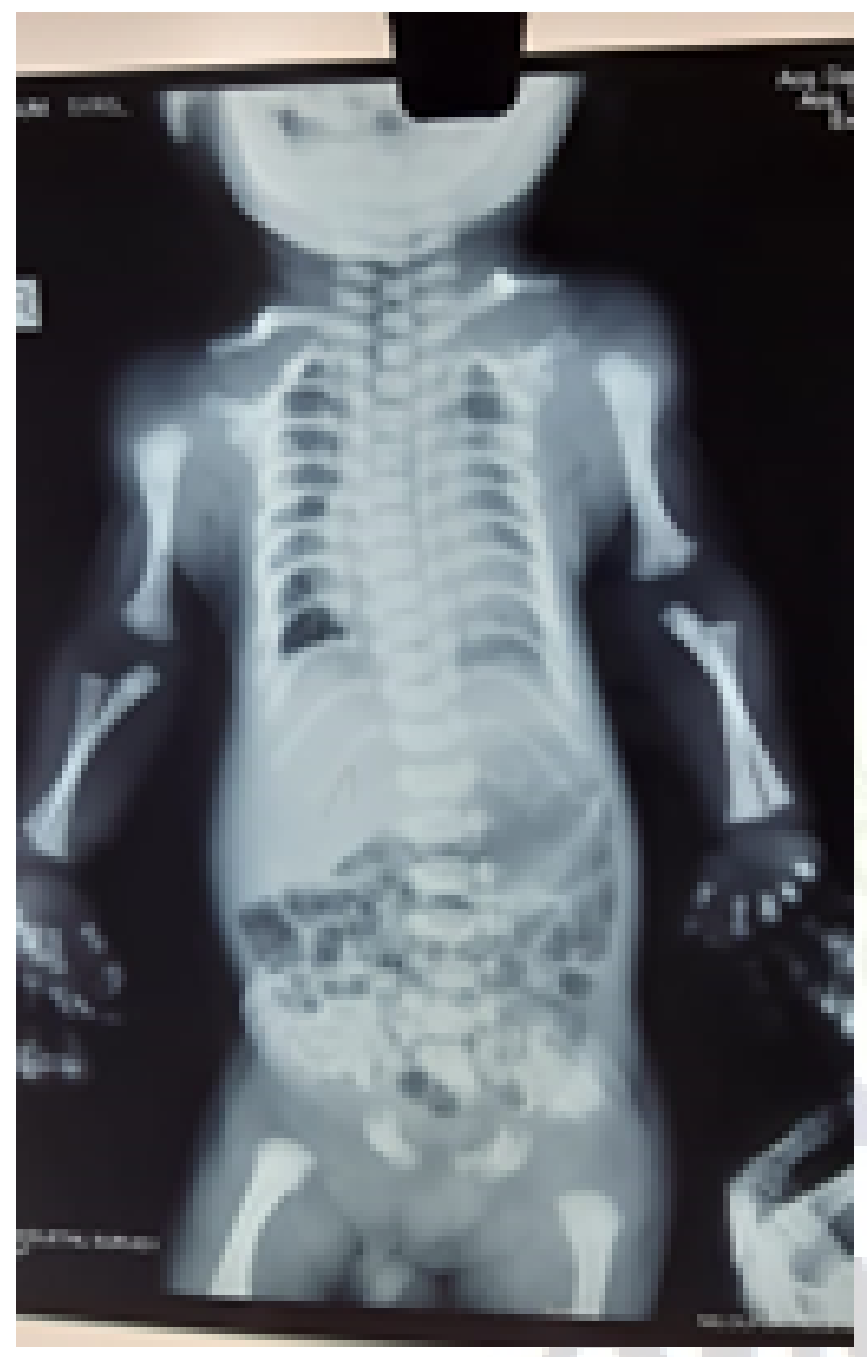

Figure 2: Asphyxiating thoracic dysplasia

Table 4: Correlation between clinical diagnosis and radiological diagnosis:

\begin{tabular}{lll}
\hline Variables & No. of Cases & Percentage \\
$\begin{array}{l}\text { Clinico- } \\
\text { radiological } \\
\text { concordance }\end{array}$ & $22 / 139$ & $22.0 \%$ \\
$\begin{array}{l}\text { Clinico- } \\
\text { radiological } \\
\text { complement }\end{array}$ & $45 / 139$ & $45.0 \%$ \\
$\begin{array}{l}\text { Clinico- } \\
\text { radiological } \\
\text { discordance }\end{array}$ & $40 / 139$ & $40.0 \%$ \\
\hline
\end{tabular}

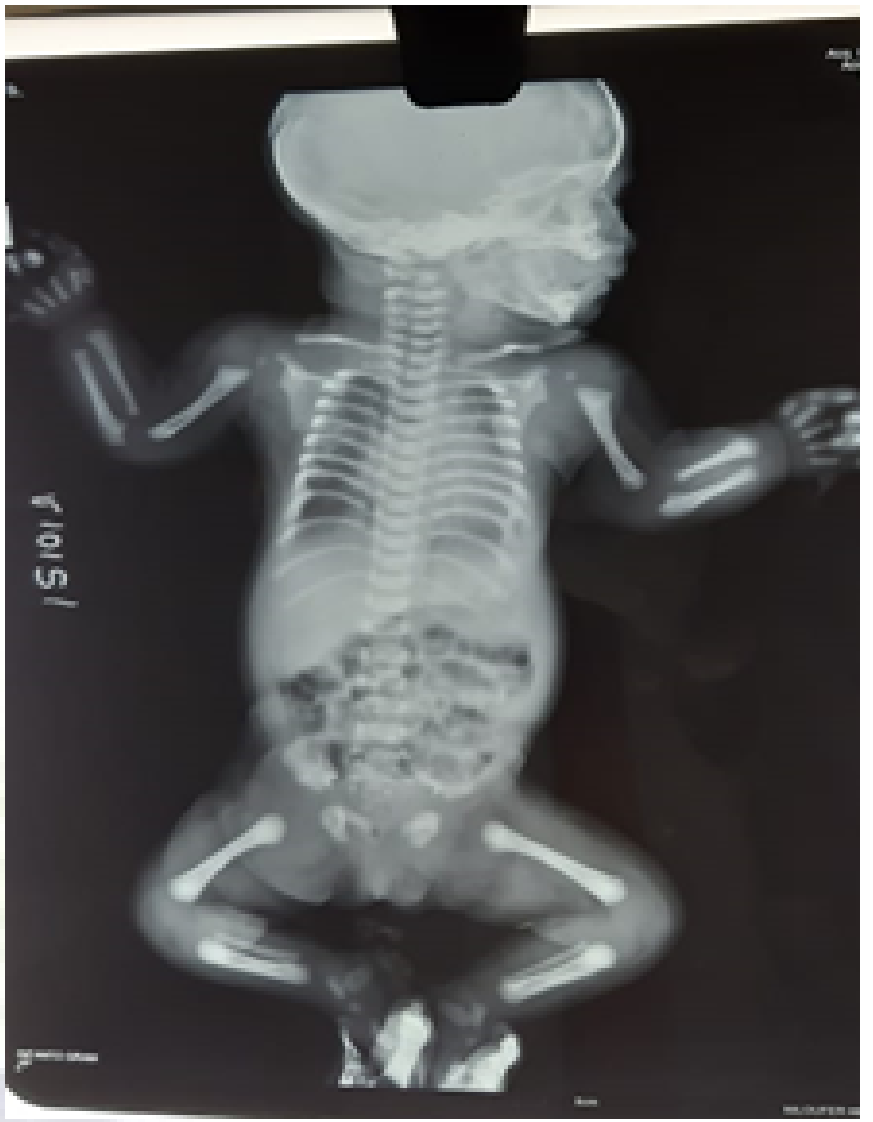

Figure 3: Ellis van crevald syndrome
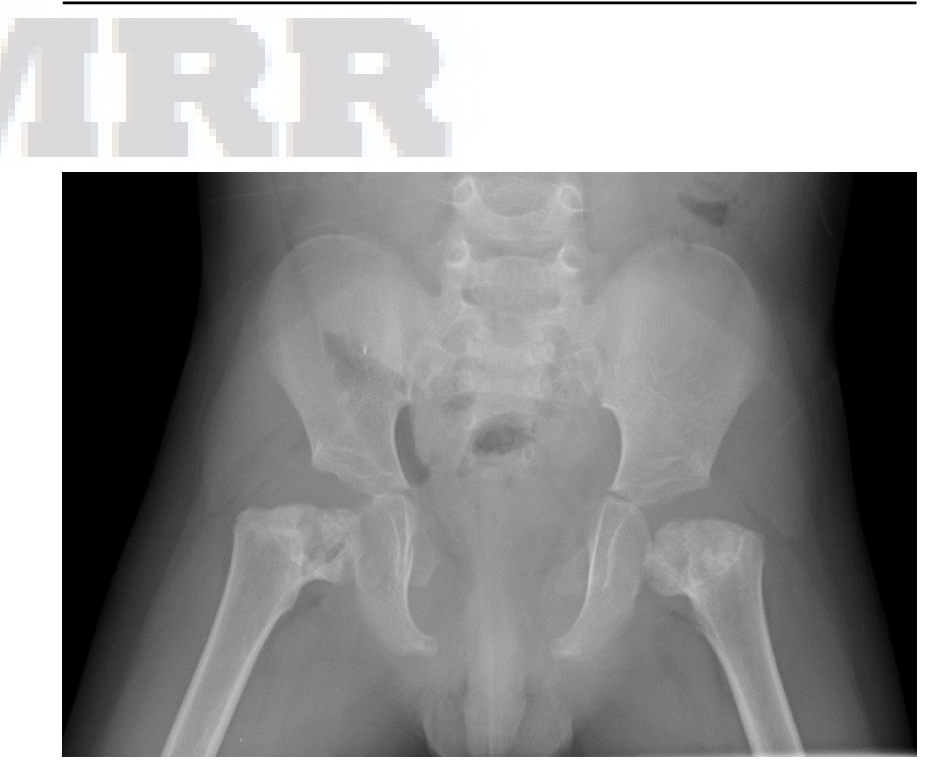

Figure 4: Metaphyseal Chondrodysplasia 


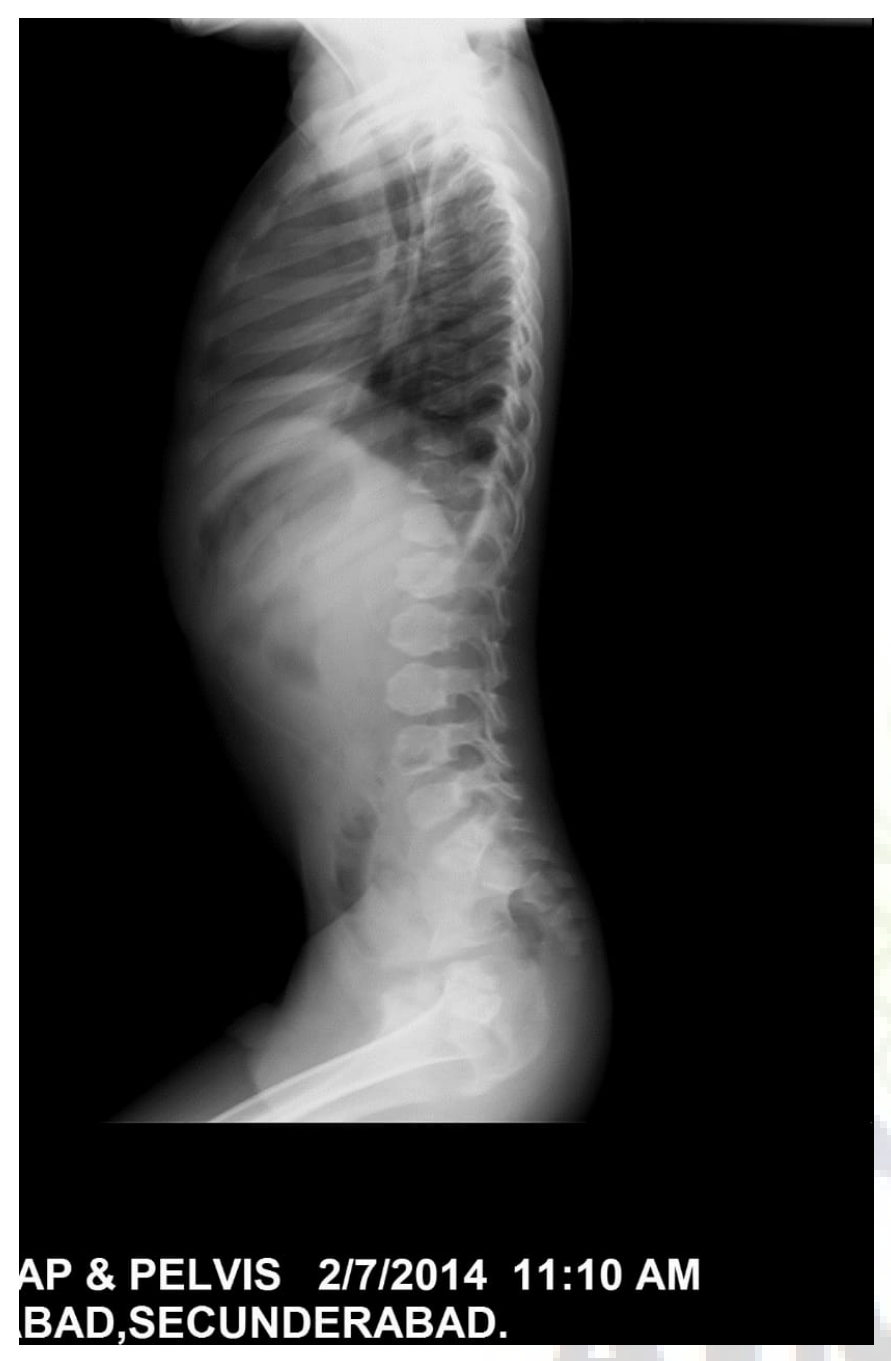

Figure 5: Metaphyseal Chondrodysplasia

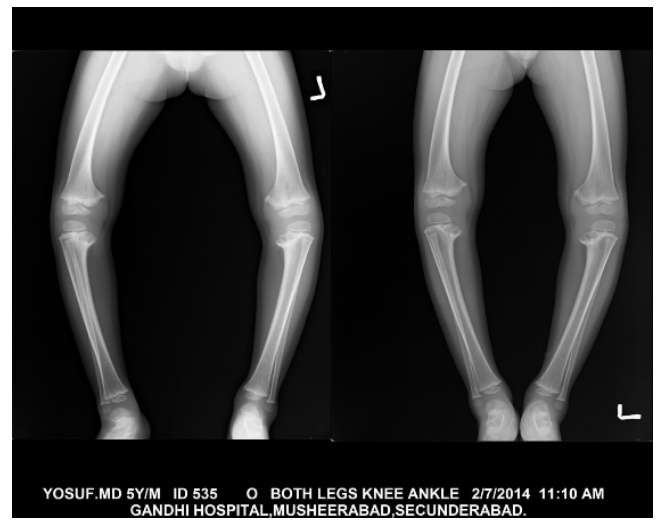

Figure 6: Metaphyseal Chondrodysplasia
Our study makes an important observation that only clinical evaluation detected only $20 \%$ of skeletal dysplasia's; and hence the importance of clinic-radiological evaluation in the proper diagnosis of skeletal dysplasia's.

Table 5: Diagnostic accuracy in clinical diagnosis of MPS \& SPED

\begin{tabular}{llll}
\hline Clinical & \multicolumn{2}{l}{ Radiological diagnosis } & Total \\
\hline MPS & MPS & Others & \\
Others & 7 & 4 & 10 \\
Total & 13 & 83 & 90 \\
\hline Sensitivity- & $45 \%$ & 87 & 100 \\
& & Specificity-98\% \\
& SPED & Others & \\
SPED & 1 & 8 & SPED \\
\hline Others & 8 & 83 & OTHERS \\
Total & 9 & 91 & TOTAL \\
\hline Sensitivity- & $11 \%$ & Specificity-25\%. \\
\hline
\end{tabular}

Among 100 cases of skeletal dysplasia's detected in our study period, most common group of dysplasia was mucopolysaccharidosis with as many as 10 cases. Among those 6 cases were detected clinically with a sensitivity of $45 \%$ and specificity of $98 \%$. Sped was the next common group of skeletal dysplasia in our study period with as many as 9 cases detected, among those clinical diagnosis was possible in only 1 case with sensitivity of $11 \%$ and specificity of $25 \%$.

\section{Discussion}

A complete study on dysplasia's in the population is difficult because majority of skeletal dysplasia's are nonlethal, many of which do not manifest at birth and may go unnoticed. Even those with major manifestations, there are difficulties in logistics with population-based studies.

All the cases in our study were classified according to the latest Nosology 2006 revision. ${ }^{[9]}$ Majority of our cases satisfied the classification. We have included these cases, because of majority of skeletal dysplasia's and syndromes overlap and have a common pathogenetic mechanism ex. Stickler syndrome, which was once considered as syndrome is now included under dysplasia's. We strongly believe that our cases which could not fit into the classification system may be included in classification system in near future. A very few Indian studies have been conducted on this. ${ }^{[10-12]}$

Among 100 cases of skeletal dysplasia's which were detected by various methods of examination like clinical, radiological (Radiography, USG, CT, MRI, echocardiography), genetic 
and biochemical tests. Among these 100 cases, 22 cases showed clinico-radiological concordance, 40 cases showed clinico-radiological complement and 45 cases showed clinicoradiological discordance. This shows that diagnosis of skeletal dysplasia's cannot be made just on clinical grounds or purely on radiological basis. This reemphasises the fact that multidisciplinary approach is more appropriate for arriving at a diagnosis in skeletal dysplasia's as in any other condition.

We were not able to show the accuracy of clinical diagnosis in all the cases, because majority of cases detected were individual cases, so we tried to include the most common skeletal dysplasia group like MPS, SPED. Diagnostic accuracy of clinical diagnosis in MPS- We had 11 cases of MPS, among which 5 cases were detected on clinical grounds with a sensitivity of $45 \%$ and specificity of $98 \%$, but diagnosis was possible in all cases by radiological examination. However, with recent development of enzyme replacement therapy (ERT) the clinico-radiological diagnosis will and soon become obsolete \& only enzymatic diagnosis will be required to help these patients with ERT. Diagnostic accuracy of clinical diagnosis in SPED- SPED (9 cases) was the next common entity and the diagnosis on clinical grounds was possible in one case with sensitivity of $11 \%$ and specificity of $25 \%$ but radiological diagnosis was possible in all cases. This shows that in majority of cases an accurate diagnosis of skeletal dysplasia's is only possible on radiological evaluation.

\section{Conclusion}

Skeletal dysplasia's are common group of disorders; they have a varied presentation, right from antenatal period to adult life. They can present with Deformity, Dwarfism, Disability and Death. These groups of disorders are not unknown but are difficult to diagnose and manage. It requires a multidisciplinary approach to identify and manage such disorders. It is ideal to have national registry of such disorders.

\section{References}

1. Kim SH, Choi J. Pathological Classification of Focal Cortical Dysplasia (FCD) : Personal Comments for Well Understanding FCD Classification. J Korean Neurosurg Soc. 2019;62(3):288295. Available from: https://dx.doi.org/10.3340/jkns.2019. 0025 .

2. Krakow D, Lachman RS, Rimoin DL. Guidelines for the prenatal diagnosis of fetal skeletal dysplasias. Genet Med. 2009;11(2):127-133. Available from: https://dx.doi.org/10. 1097/gim.0b013e3181971 ccb.

3. Offiah AC, Hall CM. Radiological diagnosis of the constitutional disorders of bone. As easy as A, B, C? Pediatr Radiol. 2003;33(3):153-161. Available from: https://dx.doi.org/10. 1007/s00247-002-0855-8.

4. Warman ML, Cormier-Daire V, Hall C, Krakow D, Lachman R, LeMerrer M, et al. Nosology and classification of genetic skeletal disorders: 2010 revision. Am J Med Genet A. 2011;155(5):943-968. Available from: https://dx.doi.org/10. 1002/ajmg.a.33909.

5. Barbosa-Buck CO, Orioli IM, da Graça Dutra M, LopezCamelo J, Castilla EE, Cavalcanti DP. Clinical epidemiology of skeletal dysplasias in South America. Am J Med Genet A. 2012;158A(5):1038-1045. Available from: https://dx.doi.org/ 10.1002/ajmg.a.35246.

6. Orioli IM, Castilla EE, Barbosa-Neto JG. The birth prevalence rates for the skeletal dysplasias. J Med Genet . 1986;23(4):328 332. Available from: https://dx.doi.org/10.1136/jmg.23.4.328.

7. Andersen PE, Hauge M. Congenital generalised bone dysplasias: a clinical, radiological, and epidemiological survey. J Med Genet . 1989;26(1):37-44. Available from: https://dx. doi.org/10.1136/jmg.26.1.37.

8. Rasmussen SA, Bieber FR, Benacerraf BR, Lachman RS, Rimoin DL, Holmes LB. Epidemiology of osteochondrodysplasias: Changing trends due to advances in prenatal diagnosis. Am J Med Genet. 1996;61(1):49-58. Available from: https://dx.doi.org/10.1002/(sici)1096-8628(19960102)61: $1<49$ ::aid-ajmg 10>3.0.co;2-w.

9. Superti-Furga A, Unger S. Nosology and classification of genetic skeletal disorders: 2006 revision. Am J Med Genet Part A. 2007;143:1-18. Available from: https://doi.org/10.1002/ ajmg.a.31483.

10. Kulkarni ML, Koshyt S, Bhagyavathi M, Kumar S, C. Skeletal Dysplasias in a hospital in southern India. Indian Pediatr. 1995;32:657-665.

11. Sankaran S, Sekerdej M, von Hecker U. The Role of Indian Caste Identity and Caste Inconsistent Norms on Status Representation. Front Psychol. 2017;8:487. Available from: https://dx.doi.org/10.3389/fpsyg.2017.00487.

12. Al-Gazali LI, Bakir M, Hamid Z, Varady E, Varghes M, Haas D, et al. Birth prevalence and pattern of osteochondrodysplasias in an inbred high risk population. Birth Defects Res A Clin Mol Teratol. 2003;67(2):125-132. Available from: https://dx. doi.org/10.1002/bdra.10009.

Copyright: (C) the author(s), 2020. It is an open-access article distributed under the terms of the Creative Commons Attribution License (CC BY 4.0), which permits authors to retain ownership of the copyright for their content, and allow anyone to download, reuse, reprint, modify, distribute and/or copy the content as long as the original authors and source are cited.

How to cite this article: Vanaja B, Veena M, Gogi S. Clinico Radiological Study of Skeletal Dysplasias. Asian J. Med. Radiol. Res. 2020;8(1):166-171.

DOI: dx.doi.org/10.47009/ajmrr.2020.8.1.30

Source of Support: Nil, Conflict of Interest: None declared. 